\title{
PHOSPHORUS SPECIES IN CORE SEDIMENT AND ITS RELATION WITH SEDIMENT CHARACTERISTICS OF PARAVUR ESTUARY, SOUTH WEST COAST OF INDIA
}

\author{
A. Santhy ${ }^{1, *}$ and R. Rejithamol ${ }^{1}$ \\ ${ }^{1}$ Department of Chemistry, Amrita Vishwa Vidyapeetham, Amritapuri-690525, (Kerala) India \\ *E-mail : santhyantherjanam@gmail.com
}

\begin{abstract}
The core sediment from two distinct zones of the Paravur estuary, one from the sea water influenced western region and other from the river water influenced eastern region were selected for estimating the different species of phosphorus. The concentration of different species of phosphorus along with iron, organic carbon and textural quality from different sediment depths of the above two locations were investigated. The average value of total phosphorus was found to be higher in fresh water influenced region than marine influenced region. Total phosphorus shows a strong positive correlation with organic carbon in both regions.
\end{abstract}

Keywords: Estuary, core sediment, phosphorus species, sediment texture, correlation.

(c) RASĀYAN. All rights reserved

\section{INTRODUCTION}

Study of sediment characteristics such as nutrients and organic carbon of an estuarine ecosystem is important to evaluate the key role of sediment organic matter and its relation to the range of estuarine contamination. Sediments can be considered as a sink as well as a source of phosphorus to the overlying water column ${ }^{1}$. The amount of phosphorus present in the aquatic ecosystem depends on both the external phosphorus load and its release and retention from the bottom sediment. The major nutrient elements in sediments are nitrogen and phosphorus of which phosphorus is the widely studied element in the environmental geochemistry, as it is the most limiting factor for primary production in most fresh water environments ${ }^{2}$. Majority of phosphorus originated from terrestrial environments buried in aquatic systems without much change, however, under favorable environmental conditions such as reduction and regeneration of organic matter results in the release of phosphorus from bottom sediment ${ }^{3}$ the rate of which depends upon its composition forms. ${ }^{4,5}$ It is also important to study the different species of sediment phosphorus as various forms have different bio-available conditions and thus have a varying potential impact on eutrophication ${ }^{6}$. Further, the sediment re-suspension also depends on its textural characteristics as well as metal oxides and hydroxides.

A detailed study on the textural characteristics of Paravur-Edava Nadayara backwater system was conducted by Madhukumar and Anirudhan ${ }^{7}$, and concluded that the textural characteristics of the estuarine sediments have a crucial role in the distribution of carbon and phosphorus. Estuarine and backwater sediments are richer in organic matter than those of the adjacent marine environment due to the proximity of anthropogenic activities of the former. Nutrients are considered as the main culprit for eutrophication in fresh water lakes, reservoirs and in the head waters of estuarine ecosystems. ${ }^{8,9}$ The prime objective of the present study is to evaluate the species of phosphorus from the core sediment samples of two environmental conditions one from marine dominant and another from fresh water influenced regions of Paravur estuary and its relationship with sediment characteristics. Also, this study attempts to find out the concentration of iron (Fe), inorganic carbon (IC), organic carbon (OC) and textural quality of the core sediments of both locations and to ascertain it relation with a concentration of phosphorus species.

Rasayan J. Chem., 11(3), 1067-1073(2018)

http://dx.doi.org/10.31788/RJC.2018.1131978

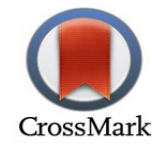


RASĀYAN J. Chem.

Vol. 11 | No. 3 |1067 - 1073 | July - September | 2018

\section{EXPERIMENTAL}

The present investigation was carried out in Paravur Kayal, in Kollam district of Kerala lying north latitude $8^{0} 18^{\prime}$ and $12^{\circ} 48^{\prime}$ and east longitudes $74^{\circ} 52^{\prime}$ and $77^{\circ} 2^{\prime}$. Samples from two locations (Fig.- 1 ) are collected for the present study, one from the western region where the sea water influence is maximum (core1) and another from eastern portion where the Ithikkara river joins the lake system and hence it is a fresh water influenced region (core2). Core sediment samples are collected from the above locations during summer season using a specially designed corer. Samples at a depth of $120 \mathrm{~cm}$ were collected. The sediments were sectioned into equal portions of $10 \mathrm{~cm}$ depths. Sufficient quantities of well-mixed core sediment samples are transferred into a plastic container and brought to the laboratory under preservation for analysis. All sediment samples are kept under refrigeration and analyzed without much time. The sediment was dried at $80^{\circ} \mathrm{C}$ homogenized and sieved. Total phosphorus (TP), Total Fe, phosphorus (P) species, IC and OC and textural characteristics were analyzed.

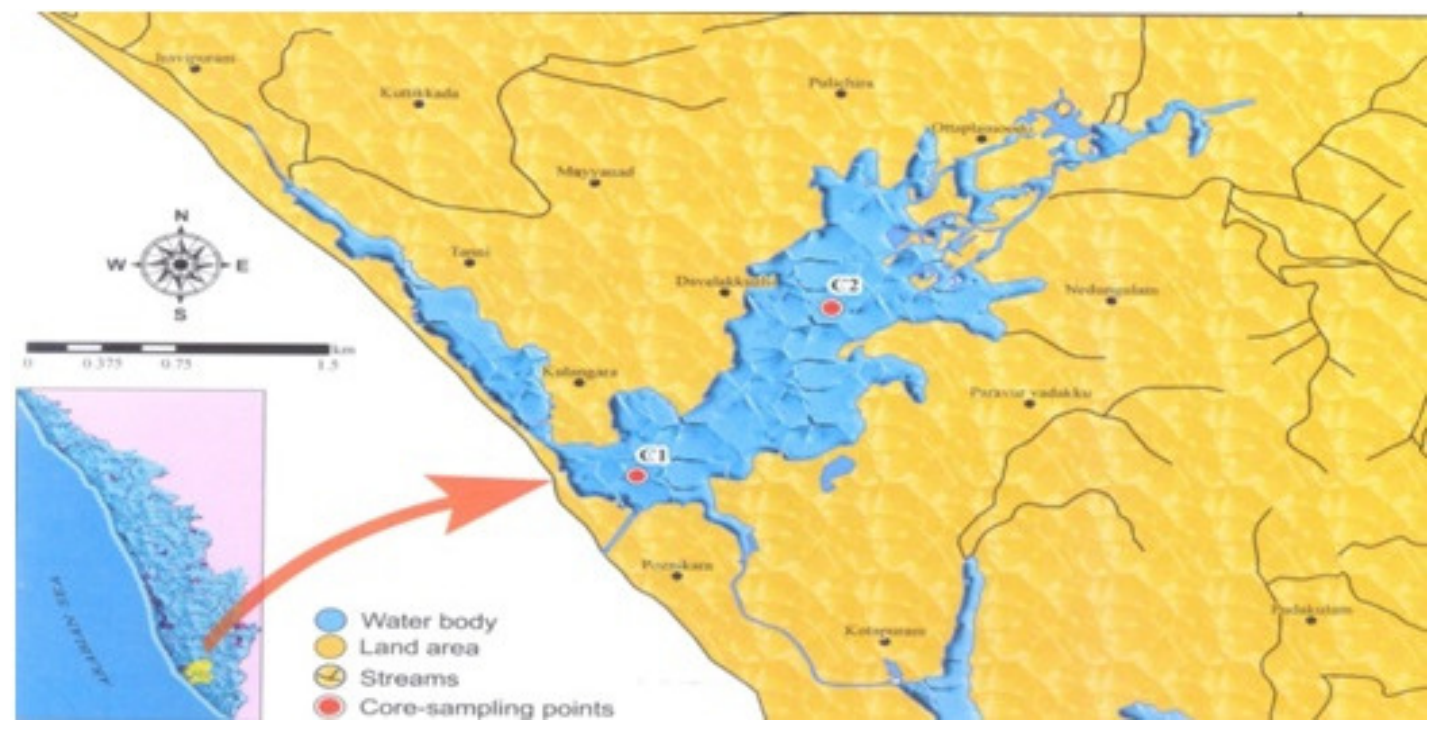

Fig.-1: Sample locations

OC was determined by exothermic heating and oxidation with potassium dichromate and $\mathrm{Conc}_{\text {. }} \mathrm{H}_{2} \mathrm{SO}_{4}$ followed by titration with excess dichromate with $0.5 \mathrm{~N}$ ferrous ammonium sulphate solution with ferroin indicator. Total Fe was determined by 1, 10 phenanthroline colorimetric method and TP was determined by a colorimetric method using ammonium molybdate-ascorbic acid method. Species of $\mathrm{P}$ were determined by the sequential extraction procedure suggested by Psenner et $\mathrm{al}^{10}$. modified by Hupfter et $\mathrm{al}^{11}$. Inorganic phosphorus (IP) is calculated as the sum of loosely bound phosphorus (LBP), iron bound phosphorus (FeP), calcium bound phosphorus $(\mathrm{CaP})$ and bound phosphorus $(\mathrm{AlP})$. The difference between TP and IP is ascertained as organic phosphorus (OP). The textural analysis of the sediment was carried out by adopting the pipette method suggested by krumblon and pettijohn ${ }^{12}$.

\section{RESULTS AND DISCUSSION}

The analytical results of 24 core sediment samples collected from the two locations of Paravur lake are given in the Tables-1 to 3. The depth-wise content of sand percentage of both cores reveals significant variation. The surface sand concentration of core 1 is relatively high with respect to core 2 which indicates the deposition of sand by the tidal action of waves than fresh water influx in the latter ${ }^{13}$. Except for the surface layer, sand in both cores recorded regular increase up to $50-60 \mathrm{~cm}$ and then shows stability to the bottom layers. A large deposition of sand in Paravur backwater system is reported by Shaji ${ }^{14}$. The average value of silt in core 1 and core 2 are $47.99 \%$ and 50.08\% respectively. Between the two cores, 1 and 2 the former records marginally higher average clay percentage compared to the latter. All samples from two cores revealed significant variation in OC spatially as well as depth-wise with higher average value in fresh water region than the marine region (Table-2). 
RASĀYAN J. Chem.

Vol. 11 | No. 3 |1067 - 1073 | July - September | 2018

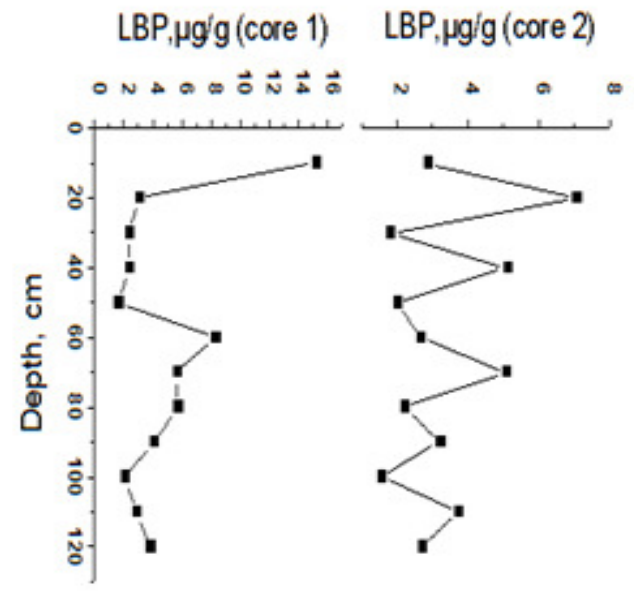

(a)

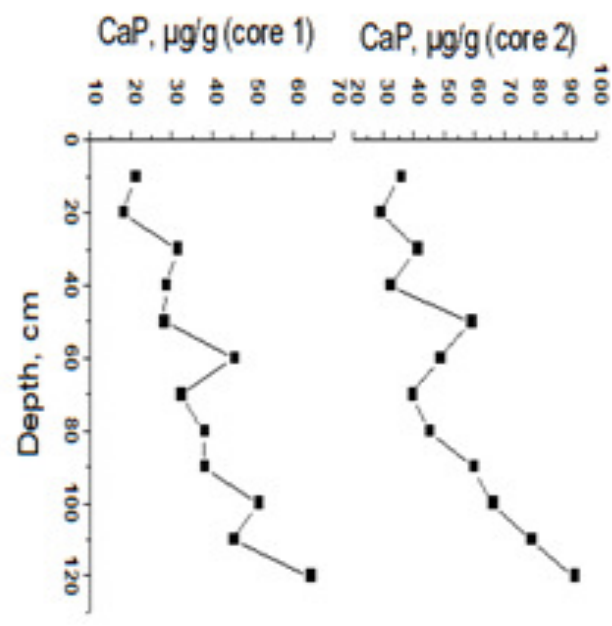

(c)

$T P, \mu g / g$ (core 1) TP, $\mu g / g$ (core 2)

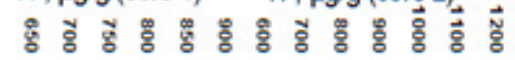
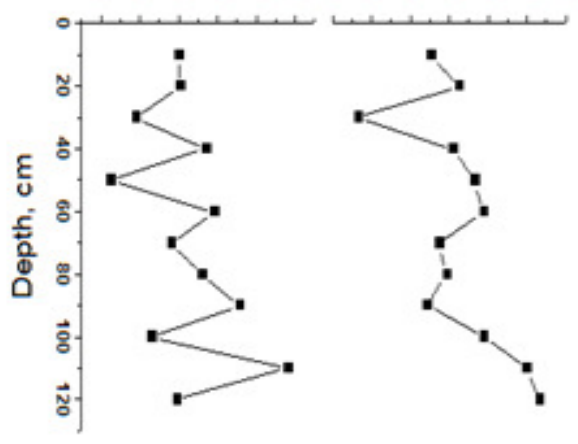

\section{FeP, $\mu g / g$ (core 1) FeP, $\mu g / g$ (core 2)}

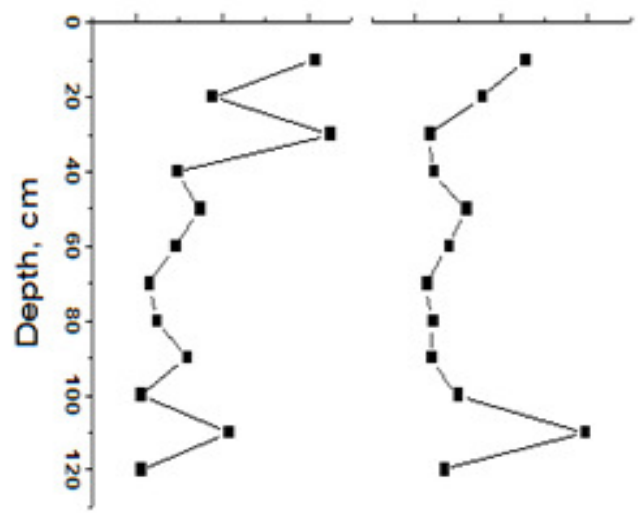

(b)

AIP, $\mu g / g$ (core 1) AIP, $\mu g / g$ (core 2)

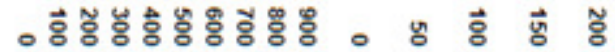

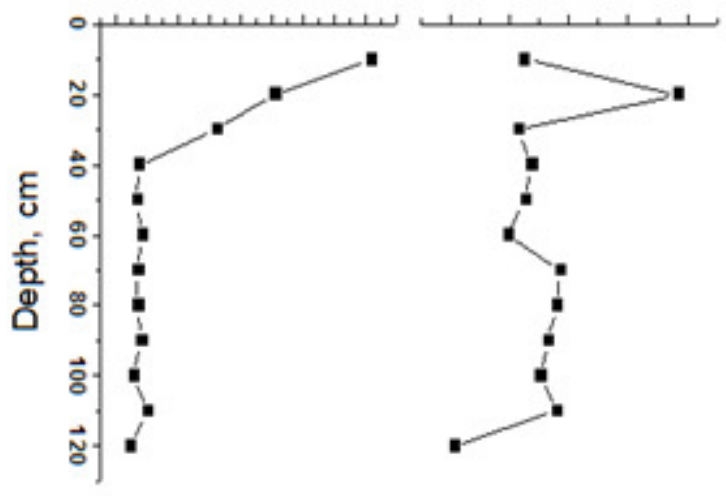

(d)

OP, $\mu g / g$ (core 1) OP, $\mu g / g$ (core 2)

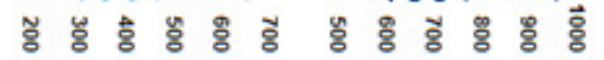

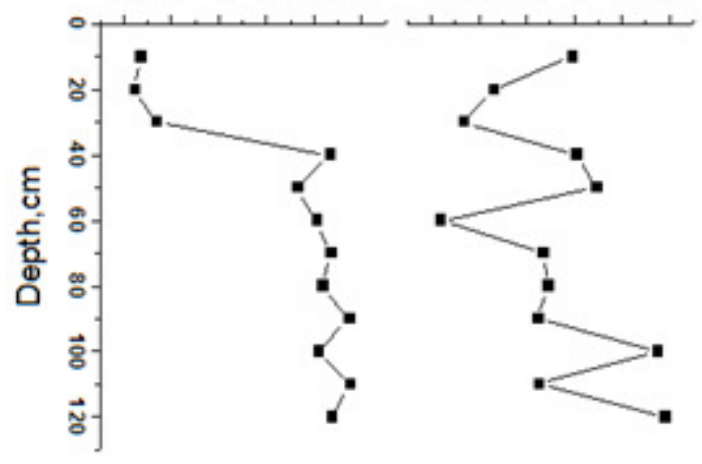

(e)

(f) 
RASĀYAN J. Chem.

Vol. 11 | No. 3 |1067 - 1073 | July - September | 2018

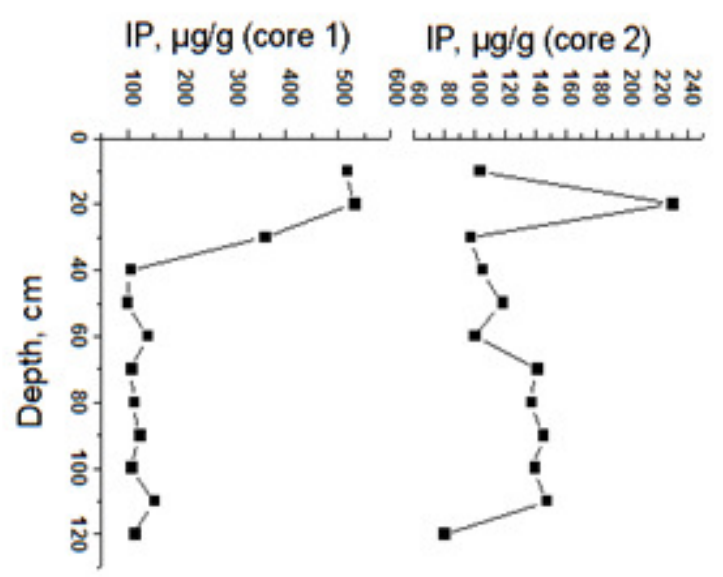

$(\mathrm{g})$

Fig.-2: The Vertical Profiles of Different Species of Phosphorus in the Core Sediment of Paravur Lake

IC shows the wide difference between the two cores (Table-2). Thus the average value of IC in core 2 is significantly (1.68\%) lower than that of core 1 (4.10\%). In core 1 the Fe content varies between $44.49 \mathrm{mg} / \mathrm{g}$ to $47.41 \mathrm{mg} / \mathrm{g}$ with depth and has an average value of $45.64 \mathrm{mg} / \mathrm{g}$. In core 2 the minimum, maximum and average content of $\mathrm{Fe}$ are $44.62 \mathrm{mg} / \mathrm{g}, 46.90 \mathrm{mg} / \mathrm{g}$, and $45.60 \mathrm{mg} / \mathrm{g}$ respectively. In core 2, the TP concentration at every depth is significantly higher than corresponding value of core 1 and it varied between $842 \mu \mathrm{g} / \mathrm{g}$ and $1132 \mu \mathrm{g} / \mathrm{g}(\mathrm{avg}-927 \mu \mathrm{g} / \mathrm{g})$ in Core 2 and the corresponding minimum, maximum and average in Core 1 are $662 \mathrm{mg} / \mathrm{g}, 890 \mathrm{mg} / \mathrm{g}$, and $763 \mathrm{mg} / \mathrm{g}$ respectively.

Among the different species of phosphorus, the concentration in core 1 is slightly higher except $\mathrm{CaP}$ compared to the corresponding concentration in core 2 . The range of concentration and average value of the four species in core 1 region are $1.52-15.2 \mu \mathrm{g} / \mathrm{g}$ (avg - $4.45 \mu \mathrm{g} / \mathrm{g}$ ) for LBP, $0.09-4.48 \mu \mathrm{g} / \mathrm{g}$ (avg $1.49 \mu \mathrm{g} / \mathrm{g})$ for FeP, $18-64 \mu \mathrm{g} / \mathrm{g}(\mathrm{avg}-37 \mu \mathrm{g} / \mathrm{g})$ for CaP and $43-507 \mu \mathrm{g} / \mathrm{g}(\mathrm{avg}-160 \mu \mathrm{g} / \mathrm{g})$ for AlP. The corresponding range and average values in Core 2 for LBP, FeP, CaP and AlP are $1.54-7.06 \mu \mathrm{g} / \mathrm{g}$ (avg $3.33 \mu \mathrm{g} / \mathrm{g}$ ), $0.25-3.92 \mu \mathrm{g} / \mathrm{g}$ (avg - $1.11 \mu \mathrm{g} / \mathrm{g}$ ), $28-92 \mu \mathrm{g} / \mathrm{g}(\mathrm{avg}-52 \mu \mathrm{g} / \mathrm{g}$ ) and $3.4-192 \mu \mathrm{g} / \mathrm{g}$ (avg -77 $\mu \mathrm{g} / \mathrm{g}$ ) respectively (Table-3). The depth wise variation phosphorus species is given in Fig.-2. The LBP is marginally higher in core 1 than core 2 . The vertical profile of LBP in fresh water region is significantly lower than that in the marine region (Fig.-2a). In the former case the values record an initial increasing trend with depth and fluctuate widely further with depth whereas in the latter case it shows a drastic decrease initially and recorded significant concentration fluctuation in the depth profile between $50-100 \mathrm{~cm}$. The concentration of $\mathrm{FeP}$ is much lower in both cores compared to other phosphorus species. In general $\mathrm{FeP}$ in core 1 a decreasing trend is noticed except at two depths, $30 \mathrm{~cm}$ and $110 \mathrm{~cm}$. Whereas in core 2 the values show an initial decrease in upper layers and thereafter shows stability towards lower depth except at 110 $\mathrm{cm}$ (Fig.-2b). The average value of $\mathrm{CaP}$ is higher in river-influenced core 2 and in both locations, the values increase with depth (Fig.-2c). The high CaP content in core 2 may be due to high concentrations of calcium mineral and the result agrees with the studies of phosphorus sediment in elsewhere ${ }^{15}$. The AlP shows nearly two-fold average enrichment in core 1 than in core 2 (Fig.-2d). In core 1 the values reveal a sudden decrease from top to $40 \mathrm{~cm}$ and thereafter indicate concentration stability. In core 2 except at depths $20 \mathrm{~cm}$ and 120 $\mathrm{cm}$ the values show the least concentration variation with depth profile. All depth profiles of the two locations show a high concentration of organic phosphorus with respect to inorganic P (Fig.-2e to Fig.-2g). Among the four forms of IP, AlP and CaP constitute the major component in both locations. However, the AlP in marine enriched location is more than double in concentration than fresh water enriched location 2 whereas $\mathrm{CaP}$ shows enrichment in fresh water region. The vertical concentration of different species of $\mathrm{P}$ is related to the physical condition of the lake system and internal output of phosphorus ${ }^{16}$. Enrichment of sediment $\mathrm{P}$ is controlled by several factors like the rate of sedimentation, textural characteristics of 
sediment, its OC content and mineralization of organic matter. Mineralization is controlled by the depth of water column and the redox condition prevailed at the sediment bottom water interface ${ }^{17}$. Among the different species of phosphorus, average organic phosphorus in core 2 is nearly $80 \%$ higher than that of core $^{18}$.

The inter relationships between different sediment parameters are assessed by matrix studies. OC and TP of both cores showed an extra ordinary correlation with an ' $r$ ' value of 0.9057 (Fig.-3). A strong interrelation between total phosphorus and organic phosphorus of core 2 is shown by an ' $r$ ' value of 0.8021 (Fig.- 4). AlP showed a strong correlation with IP in both cores (Fig.- 5). The organic content of core 1 recorded medium level correlation with TP, CaP, and OP. Such a correlation is absent in the case of core 2. Excellent correlations between sediment characteristics and phosphorus species are obtained in the core sediment of Paravur lake and it agrees with the findings of Erie lake ${ }^{19}$.

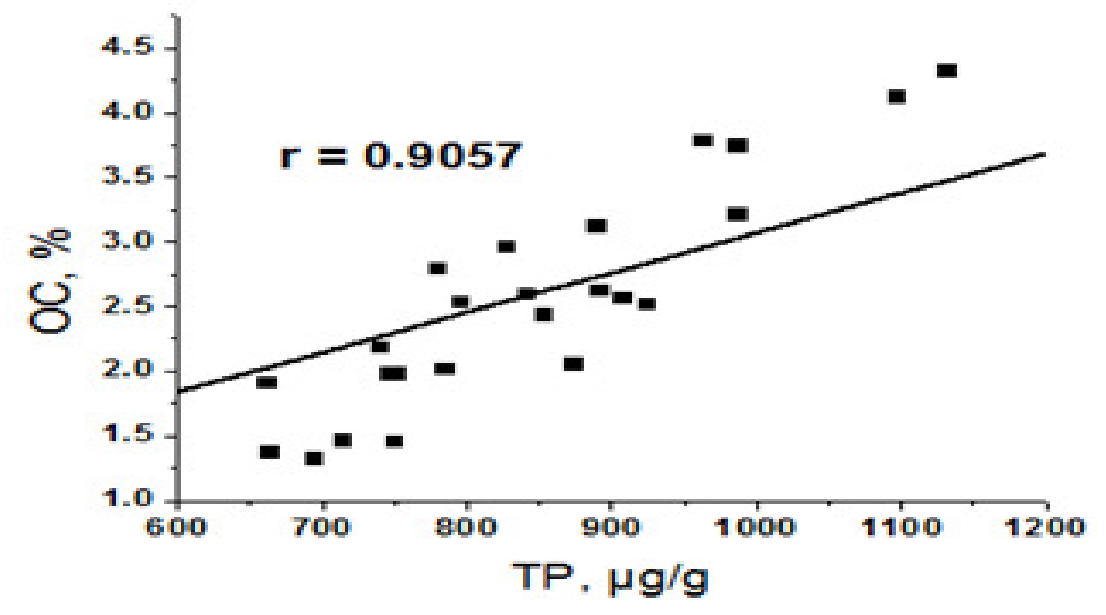

Fig.-3: Correlation of Total Phosphorus and Organic Carbon in Cores 1 and 2

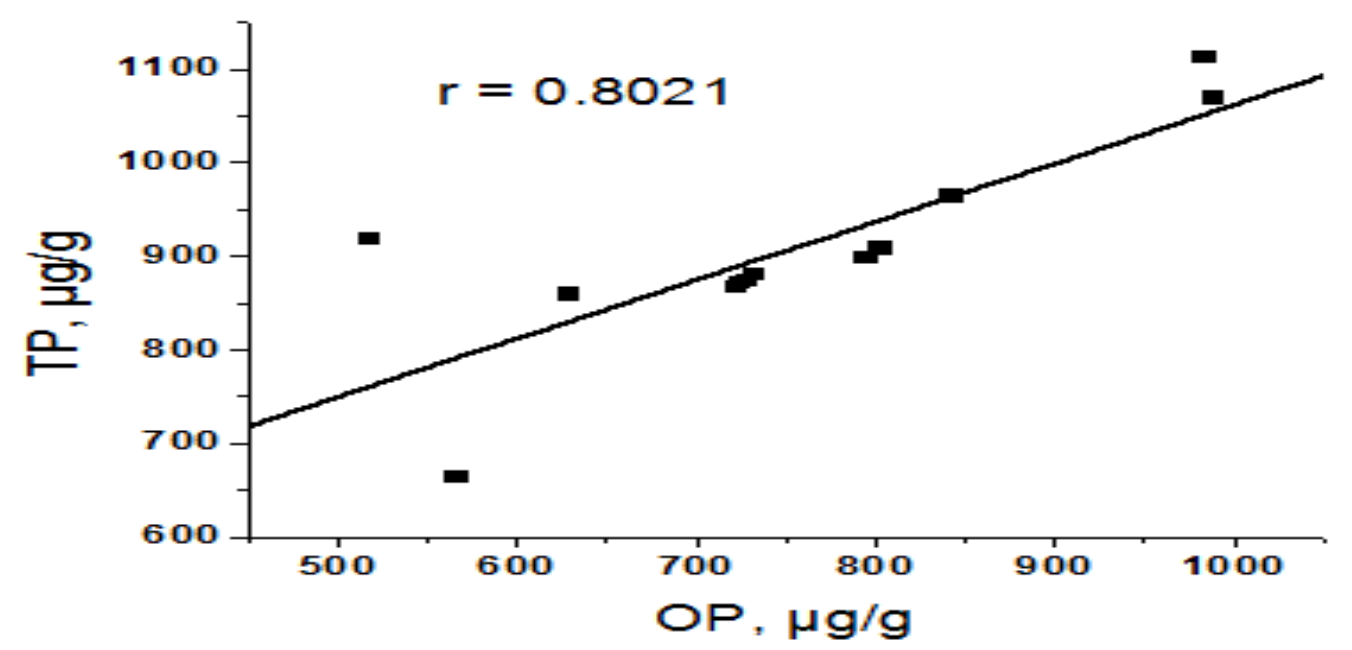

Fig.-4: Correlation of Total Phosphorus and Organic Phosphorus in Core 2

Table -1: Depth Wise Variation of Sand, Silt and Clay in Core 1 and Core 2 of Paravur Lake.

\begin{tabular}{ccccccc}
\hline $\begin{array}{c}\text { The depth of } \\
\text { sediment } \\
\text { column, cm }\end{array}$ & Sand, \% & Silt, \% & Clay, \% & Sand, $\%$ & Silt, \% & Clay, \% \\
\cline { 2 - 7 } & 6.82 & 54.11 & 39.05 & 0.25 & 54.54 & 44.24 \\
\hline 10 & 0.13 & 32.80 & 67.07 & 0.56 & 53.87 & 45.57 \\
\hline 20 & 0.17 & 43.95 & 55.88 & 1.40 & 52.77 & 47.19 \\
\hline 30 & 0.28 & 41.88 & 57.83 & 1.37 & 51.33 & 47.28 \\
\hline 40 & 4.53 & 31.91 & 63.56 & 5.00 & 65.72 & 29.29 \\
\hline 50 & & & & & &
\end{tabular}


RASĀYAN J. Chem.

Vol. 11 | No. 3 |1067 - 1073 | July - September | 2018

\begin{tabular}{ccccccc}
\hline 60 & 8.77 & 54.51 & 36.73 & 4.44 & 54.94 & 40.61 \\
\hline 70 & 2.62 & 55.45 & 41.93 & 3.87 & 59.31 & 36.82 \\
\hline 80 & 1.83 & 55.10 & 43.1 & 2.37 & 56.60 & 41.03 \\
\hline 90 & 1.63 & 54.73 & 43.66 & 1.98 & 52.74 & 45.27 \\
\hline 100 & 2.01 & 52.38 & 45.61 & 2.18 & 41.36 & 56.46 \\
\hline 110 & 2.40 & 50.03 & 47.56 & 2.49 & 26.31 & 71.20 \\
\hline 120 & 2.46 & 49.06 & 48.48 & 2.64 & 31.45 & 65.89 \\
\hline Average (avg) & 2.80 & 47.99 & 49.21 & 2.38 & 50.08 & 47.57 \\
\hline
\end{tabular}

Table -2: Depth Wise Variation of Organic Carbon, Inorganic Carbon and Total Iron in Core 1 and Core 2 of Paravur Lake.

\begin{tabular}{|c|c|c|c|c|c|c|}
\hline \multirow{2}{*}{$\begin{array}{l}\text { The depth } \\
\text { of } \\
\text { sediment } \\
\text { column, } \\
\mathrm{cm}\end{array}$} & Core 1 & & & & Core 2 & \\
\hline & $\begin{array}{c}\text { Organic } \\
\text { Carbon, } \%\end{array}$ & $\begin{array}{c}\text { Inorganic } \\
\text { Carbon, \% }\end{array}$ & $\mathrm{Fe}, \mathrm{mg} / \mathrm{g}$ & $\begin{array}{c}\text { Organic } \\
\text { Carbon, } \\
\%\end{array}$ & $\begin{array}{l}\text { Inorganic } \\
\text { Carbon, \% }\end{array}$ & $\mathrm{Fe}, \mathrm{mg} / \mathrm{g}$ \\
\hline 10 & 1.45 & 4.23 & 46.33 & 2.43 & 2.49 & 46.72 \\
\hline 20 & 1.98 & 6.73 & 46.32 & 2.52 & 1.86 & 45.83 \\
\hline 30 & 1.32 & 6.09 & 45.06 & 1.37 & 0.32 & 45.16 \\
\hline 40 & 2.01 & 5.45 & 45.76 & 2.56 & 1.56 & 46.55 \\
\hline 50 & 1.91 & 1.12 & 44.87 & 3.78 & 2.36 & 46.90 \\
\hline 60 & 2.53 & 1.75 & 44.49 & 3.21 & 3.92 & 45.51 \\
\hline 70 & 2.18 & 1.43 & 45.63 & 2.05 & 2.05 & 45.29 \\
\hline 80 & 2.79 & 2.37 & 47.41 & 2.62 & 0.19 & 45.23 \\
\hline 90 & 2.96 & 5.49 & 44.85 & 2.59 & 0.19 & 45.09 \\
\hline 100 & 1.46 & 5.49 & 46.18 & 3.74 & 1.74 & 45.34 \\
\hline 110 & 3.12 & 5.49 & 46.35 & 4.12 & 1.74 & 44.90 \\
\hline 120 & 1.98 & 6.00 & 44.46 & 4.32 & 3.30 & 44.62 \\
\hline $\begin{array}{c}\text { Average } \\
\text { (avg) }\end{array}$ & 2.14 & 4.10 & 45.64 & 2.94 & 1.68 & 45.60 \\
\hline
\end{tabular}

Table-3: The Range of Concentration of Different Species of Phosphorus in Core Sediments Found in This Study.

\begin{tabular}{|c|c|c|c|c|c|c|c|c|c|}
\hline \multicolumn{3}{|c|}{ Species of Phosphorus } & $\mathrm{TP}$ & LBP & IP & $\mathrm{OP}$ & AlP & $\mathrm{CaP}$ & $\mathrm{FeP}$ \\
\hline \multirow{3}{*}{ - } & \multirow{3}{*}{ 苞苛 } & Min & 662 & 1.52 & 97 & 222 & 43 & 18 & 0.09 \\
\hline & & Max & 890 & 15.2 & 530 & 675 & 507 & 64 & 4.48 \\
\hline & & Avg & 763 & 4.45 & 203 & 530 & 160 & 37 & 1.49 \\
\hline \multirow{3}{*}{ ठัّ $\sim$} & \multirow{3}{*}{ 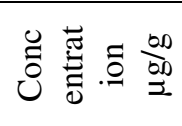 } & Min & 842 & 1.54 & 99 & 564 & 3.43 & 28 & 0.25 \\
\hline & & Max & 1132 & 7.06 & 230 & 1033 & 192 & 92 & 3.92 \\
\hline & & Avg & 927 & 3.33 & 133 & 794 & 77 & 52 & 1.11 \\
\hline
\end{tabular}

\section{CONCLUSION}

This paper has presented data on different forms of sedimentary phosphorus in the Paravur lake. The core sediments from two locations of Paravur lake showed medium to excellent positive correlation in all parameters like textural quality, IC, OC, Fe and different species of $\mathrm{P}$. The lake is affected by various environmental factors like contamination from agricultural activities of basin area, coconut husk retting activities etc. Both core samples showed low differences in OC and IC. All species of phosphorus shows remarkable variation between fresh water influenced region and sea water influenced region. The concentrations of LBP, FeP and AlP is found to be higher in the marine influenced region of the lake compares to river influenced region. The $\mathrm{OP}$ fractions and $\mathrm{CaP}$ in paravur sediment is higher in the river influenced region than in marine influenced region.

\section{ACKNOWLEDGMENT}

The authors are extremely thankful to Dr. K. Narendra Babu, the former head of Chemical Science Division, National Centre for Earth Science Studies, Thiruvananthapuram for constant support and encouragement. 


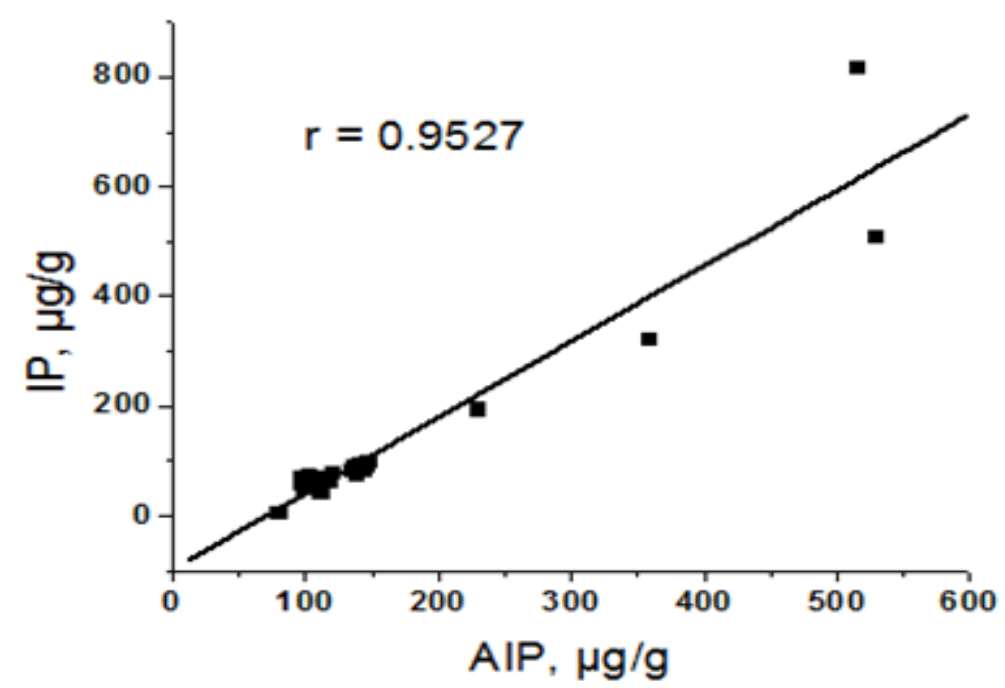

Fig.-5: Correlation of Aluminium Bound Phosphorus and Inorganic Phosphorus in Core 1 and 2

\section{REFERENCES}

1. L. Wang, T. Liang, B. Zhong, K. Li, Q. Zhang, Aquat Geochem, 20, 1(2014), DOI:10.1007/s10498014-9232-0

2. H.L. Golterman, The Chemistry of Phosphate and Nitrogen Compounds in Sediments, Kluwer Academic Publishers, Dorsrecht (2004).

3. H.S. Jensen, P. B. Mortensen, F.O. Andersen, E. Rasmussen, A. Jensen, Limnology and Oceanography, 40, 908(1995).

4. Q.X. Zhou, C. E Gibson, Y. M. Zhu, Chemosphere, 21, 221(2001).

5. A. Peter, B. Anju, D. Sullivan, C. Smitha, N. K. Kothurkar, Published in Global Humanitarian Technology Conference, IEEE Xplore pp. 452 - 456 (2013).

6. Z.Z. Hua, X. Q. Zhu, X. R. Wang, Acta Scientiae Circumstantiate, 25, 100(2000).

7. A. Madhukumar, T. S. Anirudhan, Indian J.Mar. Sci. 24, 186(1995).

8. Claire. L. Schelske, Eutrophication: Focus on Phosphorus. Science (New York, N.Y.), 324,722(2009), DOI: $10.1126 /$ science.324_722

9. X. Wang, Proc Environ Sci, 12, 379(2012).

10. R. Psenner, B. Boström, M. Dinka, Archiv Hydrobiol Beih Ergeb Limnol, 30, 98(1988)

11. M. Hupfer, R. Gachter, R. Giovanoli, Aquatic Science, 57, 305-324(1995),DOI: 10.1007/BF00878395

12. W.C. Krumblon, F.J. Pettijohn, Manual of sedimentary petrography. Appleton- Century, New York, pp. 549 (1938)

13. B.P. Dass Batvari, V.E. N. Mariappan, Rasayan J. Chem., 9, 424(2016).

14. E. Shaji, Pozhikkara irrigation Regulator - Environmental Impacts on Land and Water, A Case Study, In Proceedings of Fourteenth Kerala Science Congress, Kochi, pp. 3-7 (2002)

15. H.J. Luo, D.F. Liu, and Y.P. Huang, Journal of Environmental Protection, 6, 281(2015), DOI: 10.4236/jep.2015.64028

16. S. M. Liu., J. Zhang, D.J. Li, Coastal Shelf Science, 27,209(2004), DOI: 10.1016/j.ecss.2003.08.009

17. B. Craca, J. Bolalek, Applied Geochemistry, 13, 319(1998).

18. P. S. Bytyci1, F.N. Zhushi Etemi, M.A.Ismaili1, Sh.A. Shala, M.S. Serbinovski, H.S. Çadraku, O.B. Fetoshi, Rasayan J. Chem., 11, 554 (2018), DOI: 10.7324/RJC.2018.1122087

19. J. D. H. Williams, J.K Syers, S.S Shukia , R.F Harris, D.E Amstrong, Environ Sci Technol., 5, 113 (1971)

[RJC-1978/2018] 